OPEN ACCESS

ISSN 25482254 (online)

ISSN 20893833 (print)

Edited by:

Mahardika Darmawan Kusuma

Wardana

Reviewedby:

Emy Pratiwi

${ }^{*}$ Correspondence:

Nurman Mirmanto

nurman.mirmanto@gmail.com

Received: 23 Oktober 2020 Accepted: 22 April 2021

Published: 26 April 2021

Citation:

Mirmanto N, Harun Joko Prayitno,

Anam Sutopo, Laili Etika

Rahmawati, and Choiriyah

Widyasari (2021) A Shift In The

Politeness Actions of Grade 5

Elementary School Students With

a Javanese Cultural Background

Education in Senior High School.

Pedagogia: Jurnal Pendidikan. 10:2.

doi:10.21070/pedagogia.v10vi2i.10

\section{A Shift in The Politeness Actions of Grade 5 Elementary School Students With a Javanese Cultural Background}

\section{Pergeseran Tindak Kesantunan Peserta Didik Kelas 5 Sekolah Dasar Dengan Berlatar Belakang Budaya Jawa}

\author{
Nurman Mirmanto ${ }^{*}$, Harun Joko Prayitno ${ }^{2}$, Anam Sutopo $^{3}$, Laili Etika Rahmawati ${ }^{4}$, \\ Choiriyah Widyasari ${ }^{5}$ \\ Universitas Islam Negeri Sunan Ampel Surabaya, Indonesia
}

The shift in the act of politeness directive set in Javanese culture in elementary school children began to shift and shift in a negative direction. This study aims: (1) to describe the form of shift in the act of politeness directive class 5 students in interacting with teachers with Javanese cultural backgrounds in elementary school. (2) To find out the factors that influence the shift in directive politeness acts towards teachers with Javanese cultural background. The approach used in this research is descriptive qualitative. Data collection using the Case study method: direct observation, listening and field records (Whaatsaap recording). Results of the study: 1) language politeness acts in grade 5 students of SDN Polokarto 01 in communicating and interacting with speech partners are still very low, a shift in politeness in language with a Javanese cultural background needs to be fostered or efforts to restrain the level of shift so as not to deviate too much from the upload .2.2) factors that make the shifting politeness act further include a) family, and parents. b) demographic factors in the surrounding environment. 3) strategic efforts to withstand the shift by reversing the existing cultural norms in society by prioritizing 1) Angon Rasa, 2) Adu Rasa. 3) Board 4) Humility 5) Respect 6) Salira tepa attitude.

Keywords: Politeness Actions, Elementary School Students, Javanese Culture

Pergeseran tindak kesantunan direktif berlatar budaya jawa dalam lingkungan anak SD mulai beralih dan bergeser ke arah yang negatif. Penelitian ini bertujuan : (1) untuk Mendiskripsikan bentuk pergeseran tindak kesantunan direktif peserta didik kelas 5 dalam berinteraksi dengan guru berlatar belakang budaya jawa di SD. (2) untuk Mengetahui faktor-faktor yang mempengaruhi pergeseran tindak kesantunan direktif terhadap guru dengan berlatar belakang budaya jawa. Pendekatan yang digunakan dalam penelitian ini adalah diskriptif kualitatif. Pengumpulan data dengan menggunakan metode Case study : observasi langsung, simak dan rekam lapangan (rekaman Whaatsaap). Hasil dari penelitian: 1) tindak kesantunan berbahasa pada peserta didik kelas 5 SDN Polokarto 01 dalam berkomunikasi dan berinteraksi dengan mitra tutur masih sangat rendah, pergeseran Kesantunan berbahasa berlatar 
belakang budaya jawa perlu dilakukan pembinaan atau upaya untuk menahan tingkat pergeseran supaya tidak terlalu menyimpang dari unggah ungguh.2) faktor yang menjadikan semakin jauhnya pergeseran tindak kesantunan diantaranya adalah a)faktor keluarga, dan orang tua.b) faktor demografis lingkungan sekitar. 3) upaya strategi dalam menahan pergeseran yakni dengan mengambalikan pada norma budaya yang ada dalam masyarakat dengan lebih mengutamakan 1) Angon Rasa, 2) Adu Rasa. 3) Empan papan 4) Sifat rendah hati 5) Sikap hormat 6) Sikap tepa salira.

Kata Kunci: Pergeseran, Tindak Kesantunan, Peserta Didik SD, Budaya Jawa 


\section{PENDAHULUAN}

Kepribadian seseorang dapat dilihat dari cara seseorang berbahasa. Bertutur kata yang baik menjadi indikator dalam mengidentifikasi seseorang ketika berkomunikasi dengan orang lain, sehingga seseorang yang menjadi tahu watak dan karakter penutur dari cara bicaranya. Tuturan seseorang yang kurang baik, akan memberikan makna yang kurang baik. Begitu sebaliknya penutur yang tuturannya baik akan memberikan anggapan baik terhadap kepribadianya.

Bahasa sebagai salah satu alat untuk berkomunikasi, baik secara lisan maupun tulis. Bahasa menjadi suatu sistem bunyi bermakna yang dipergunakan untuk komunikasi oleh kelompok manusia. Menurut Kridalaksana dan Djoko Koentjono (Chaer, 2014:32), pengertian bahasa adalah sistem lambang bunyi yang arbiter yang digunakan oleh para anggota kelompok sosial untuk bekerjasama, berkomunikasi, dan mengidentifikasi diri. Bahasa itu menjadi alat yang sangat efektif dalam menunjukkan keberadaan seseorang asal usul seseorang. Melalui bahasa, setiap individu dapat berinteraksi dengan orang lain.

Budaya Jawa yang identik dengan tatakrama unggahungguh sangatlah memegang dan memberikan posisi yang tinggi terhadap nilai-nilai luhur dalam berbudaya, bertingkah laku maupun bertutur kata. Interaksi antar kasta, antar jenjang usia dan antar mitra tutur harus selalu diperhatikan dalam bertutur kata atau berkomunikasi lisan. Jika terdapat seseorang yang kurang bisa menerapkan cara bertutur kata menurut unggah ungguh yang benar, biasanya akan mendapatkan penilaian negatif dalam suatu komunitas.

Tatakrama seharusnya selalu diperhatikan dalam berinteraksi di lingkungan masyarakat jawa dengan latar belakang budaya jawa. Keluhuran bahasa jawa, budaya jawa yang sudah melekat dan mendarah daging dalam sanubari masyarakat jawa. Namun pada era dan zaman milenial ini, pergeseran tindak kesantunan direktif dalam bertanya dan menjawab dengan berlatar budaya jawa mulai beralih dan bergeser ke arah yang negatif. Tingkat penguasaan akan unggah-ungguh dan tatakrama yang mulai memudar, semakin lama semakin menipis dari tatabaku yang seharusnya ada dalam budaya jawa. Hal ini terjadi juga dalam lingkungan anak SD ketika berinteraksi dengan sesama maupun guru sering sekali tidak memperhatikan unggah-ungguh menurut budaya jawa.

Demikian hal yang sama terjadi pula pada peserta didik SD Negeri Polokarto 01 Kecamatan Polokarto Kabupaten Sukoharjo. Tindak kesantunan direktif terhadap guru ketika berinteraksi baik dalam pembelajaran maupun dalam bertegur sapa, berinteraksi dengan guru, dengan sesama peserta didik yang lebih tua usianya maupun dengan adik kelas dengan usia yang lebih muda terasa sangat kurang. Boleh dikatakan unggah-ungguh atau tatakrama dalam berkomunikasi dengan latar belakang budaya jawa sangat jauh dari aturan ada dimasyarakat. Meskipun aturan tersebut merupakan aturan yang tidak tertulis, namun telah menyatu bahkan mendarah daging dengan kepribadian tingkah laku ( muno muni) masyarakat jawa.

peserta didik SD Negeri Polokarto 01 yang terletak di area pedesaan yang masih kental dengan segala kearifan lokal dan menjunjung tinggi kebudayaan jawa yanng adi luhung. Letak geografis lokasi tempat tinggal peserta didik SD Negeri Polokarto 01 yang tidak jauh dari sumber kebudayaan jawa yakni Keraton Kasunanan Surakarta Hadiningrat. Kondisi geografis tersebut seharusnya menjadi pelestari tindak kesantunan direktif terhadap guru dengan berlatar belakang budaya jawa. Namun demikian kenyataan berbanding terbalik dengan segala teori yang ada.

Pergeseran tindak kesantunan direktif peserta didik terhadap guru dengan berlatar belakang budaya jawa ini, tentunya tidak bisa dibiarkan berjalan terus menjauh, menjauhi pranatan tata aturan yang ada di masyarakat yang berbudaya jawa. Maka perlu adanya upaya untuk menahan bagaimana pergeseran negatif tindak kesantunan direktif peserta didik tersebut menjadi lebih luas,sehingga menjadi penyebab luntur bahkan hilangnya unggah-ungguh atau tatakrama dalam berinteraksi dengan sesama, guru, masyarakat dengan berlatar belakang budaya jawa. Upaya menahan pergeseran itu harus dicari sebagai solusi terhadap lunturnya kebudayaan yang adi luhung yang ada di tanah jawa. Pergeseran tindak kesantunan direktif peserta didik kelas 5 terhadap guru tersebut, menjadikan fokus penelitian yang akan dilakukan oleh peneliti dalam melaksanakan penelitian.

Rumusan masalah pada penelitian ini adalah :(1) Bagaimanakah pergeseran tindak kesantunan direktif peserta didik kelas 5 dalam berinteraksi terhadap guru berlatar belakang budaya jawa di SD Negeri Polokarto 01?, (2) Faktor apa saja yang mempengaruhi pergeseran tindak kesantunan peserta didik kelas 5 SD Negeri Polokarto 01 dengan berlatar belakang budaya jawa?. (3) Bagaimana strategi menahan pergeseran negatif tindak kesantunan direktif peserta didik kelas 5 dalam berinteraksi dengan guru berlatar belakang budaya jawa di SD Negeri Polokarto 01? Berdasarkan fokus peneelitian di atas, tujuan dalam penelitian ini adalah : (1) Mendiskripsikan bentuk pergeseran tindak kesantunan direktif peserta didik kelas 5 dalam berinteraksi dengan guru berlatar belakang budaya jawa di SD Negeri Polokarto 01. (2) Mengetahui faktor-faktor yang mempengaruhi pergeseran tindak kesantunan direktif terhadap guru dengan berlatar belakang budaya jawa.(3) Mendiskripsikan strategi menahan pergeseran negatif tindak kesantunan direktif peserta didik kelas 5 dalam berinteraksi dengan guru berlatar belakang budaya jawa di SD Negeri Polokarto 01.

Penelitian ini diharapkan memeberikan capaian tujuan penelitian secara optimal, mampu memberikan cara dalam mengarahkan pergeseran tindak kesantunan ke arah positif. Manfaat teoritis dalam kegiatan pembelajaran di lingkungan $\mathrm{SD}$, baik itu bahasa Jawa maupun bahasa Indonesia memberikan pengalaman belajar bagi peserta didik dalam bertutur kata yang baik sesuai dengan pola kesantunan dalam budaya jawa. Manfaat praktis : (1) peserta didik mendapatkan cara bertutur kata yang baik, (2) Meningkatkan tindak kesantunan positif peserta didik terhadap guru. (3) sebagai motivasi dan evaluasi dalam memberikan tanggapan cara menahan pergeseran tindak kesantunan yang negatif oleh peserta didik terhadap guru dengan berlatar belakang budaya jawa

Penelitian yang lain yang relevan dilakukan oleh Masfufah, Nurul (2012) dengan judul penelitian : "Skala Kesantunan 
Bentuk Tuturan Direktif Berdasarkan Persepsi peserta didik Di SMAN 1 Surakarta". Dengan hasil penelitian : bahwa urutan kesantunan bentuk tuturan direktif berdasarkan persepsi peserta didik dari santun ke paling santun. Persamaan dengan peneliti pada kajian kesantunan, sedangkan perbedaan dengan peneliti pada objek penelitian yaitu peserta didik SMA 1 Surakarta dan peserta didik SD Kelas 5.

Teori tentang Kesantunan telah banyak ditulis oleh para pakar dan ahli. Lakoft (Jumanto,2017:81) mengkaji bahwa kesantunan berdasarkan kaidah dibedakan menjadi 3 yaitu (1) jangan memaksa ( Don't impose), (2) berikan pilihan ( give options), (3) buatlah seseorang menjadi nyaman, maka bersikaplah ramah( make A feel good, be freindly). Budaya menjadi unsur penting serta pengaruh terhadap sosial, penghormatan, pergaulan .

Kesantunan dapat diunngkapkan dalam bentuk yang berbeda-beda. Menurut Brown dan Levinson (Jumanto, 20017: 83) kesantunan dapat dibagi menjadi dua yakni strategi kesantunan positif dan strategi kesantunan negatif. Strategi kesantunan positif (positif politness strategis) dapat menunjukkan kedekatan, hubungan baik antara penutur dan petutur. Sedangkan strategi kesantunan negatif (negative politness strategies) mengukur jarak sosial antara penutur dan petutur. Tindak tutur dengan menggunakan kesantuanan negatif dapat dilakukan dengan beberapa strategi atau cara oleh penutur. Sepuluh cara yang dapat dilakukan oleh penutur adalah sebagai berikut: (1) menggunakan tindak tutur tak langsung, (2) menggunakan pagar, (3) bersikap pesimistik, (4) melakukan imposisi seminimal mungkin, (5) menggunakan bentuk penghormatan, (6) meminta maaf,(7) menghindari menggunakan kata "saya", (8) menggunakan tindak tutur yang mengancam muka, (9) menggunakan bentuk normalisasi, (10) menyatakan seolah-olah berhutang budi.

Berbeda dengan pendapat yang diungkapkan oleh Leech (Jumanto, 2017: 87) kesantunan memiliki 2 prinsip kesantunan yaitu : (a) meminimalkan perasaan santun, (b) memilih ujaran yang bersifat tidak merendahkan harga diri orang lain. Dari beberapa pendapat dan teori para ahli tentunya memiliki pengaruh terhadap penutur maupun petutur. Dalam berkomunikasi dan berinteraksi terhadap orang lain akan memberikan dampak terhadap harga diri dan kehormatan serta status sosial seseorang dalam masyarakat.

Masyarakat Jawa yang terbagi dalam tiga wilayah besar di Indonesia yakni Jawa Barat, Jawa Tengah dan DIY, Jawa Timur. Memiliki tiga karakter perbedaan yang sangat mencolok dalam berkomunikasi secara verbal. Dari ketiga wilayah Pulau Jawa tersebut tentunya Jawa Tengah-DIY yang memiliki karakter berkomunikasi tindak kesantunan yang halus. Prinsip budaya (cultural) sangat mempengaruhi gaya dan cara penutur menyampaikan ide dalam berkomunikasi di masyarakat.

Dalam berkomunikasi orang dengan latar belakang budaya jawa memiliki prinsip kesantunan. Menurut Prayitno (2011) terdapat dua prinsip orang jawa yang utama yaitu : (1) prinsip menghormati orang lain, (2) menghindari adanya konfrontasi dengan orang lain.

Prinsip pertama dalam budaya jawa biasanya bersifat hierarkis. Sehingga orang dengan berlatar belakang budaya jawa perlu mengetahui kedudukannya di masyarakat, perlu mengetahui perbandingan usia, perlu mengetahui taraf ekonomi dalam masyarakat. Orang dengan posisi kedudukan yang lebih rendah atau kecil seharusnya bisa menempatkan diri untuk lebih memberikan penghormatan terhadap posisi kedudukan, usia maupun kasta ekonomi.

Prinsip yang kedua masyarakat jawa sangat menjaga keharmonisan dalam kehidupan bermasayarakat. Dalam falsafah jawa sering sekali disebutkan "rukun agawe santoso, crah agawe bubrah" sering sekali dijadikan maskot, bahkan branding desa-desa. Dalam setiap pertemuan RT RW falsafah tersebut selalu di pakai sebagai motivasi warganya untuk senantiasa menjaga keharmonisan hidup berkeluarga maupun bermasyarakat.

Kesantunan dapat pula dikatakan sebuah etika yakni tatacara kebiasaan yanng berlaku di masyarakat sehingga kesantunan menjadi sebuah kesepakatan sosial yang disepakati masyarakat atau komunitas tertentu dalam memberikan penghargaan terhadap suatu perlakuan atau tingkah laku. Dalam masyarakat jawa kesantunan sering disebut dengan istilah "tatakrama" atau "unggah-ungguh". Kesantunan (Politeness) merupakan perilaku yang diekpresikan dengan cara yang baik dan beretika (Zamzani dkk, 2010: 2). Kesantunan dapat berbeda aplikasinya antara suatu kultur yang satu dengan kultur yang lain.

Kesantunan dalam masyarakat jawa baik secara komunikasi verbal maupun non verbal Gunarwan Asim (Jumanto, 2017: 102) menagjukan bidal yang dipraktekkan oleh masyarakat jawa, diantaranya yaitu : (1) Kurmat (hormat), (2) Andhap Asor/rendah hati, (3) tepo sliro/ jaga diri, (4) Empan papan/ mampu melihat situasi, (5) Mikul dhuwur, mendhem Jero/menjunjung tingi orang tua, maafkan kesalahan mereka, (6) Butuh, Pakewuh/ yang lebih perlu, haruslah malu. Bidal kesantunan ini dalam masyarakat jawa senantiasa di junjung tinggi sebagai kearifan lokal yang layak untuk dilestarikan.

\section{METODE}

Penelitian ini dapat dikelompokkan dalam jenis penelitian Kualitatif sebuah pendekatan yang sering juga disebut investigasi, peneliti mengumpulkan data dengan cara bertatap muka langsung dan berinteraksidengan orang yang berada di tempat penelitian (Syamsudin dkk, 2006:73). Penelitian ini menggunakan pendekatan kualitatif, karena berhubungan dengan permasalahan manusia yang secara fundamental berhubungan dengan penngamatan. Dalam memperoleh data dilakukan dengan melakukan observasi dan wawancara pada peserta didik, orang tua, dan guru. Moelong (2011:6) bahwa Penelitian Kualitatif adalah penelitian yang digunakan untuk memahami tentang apa yang dialami oleh subjek penelitian misalnya perilaku, persepsi,motivasi, dan tindakan lain-lain yang bersifat holistik dan dengan cara diskripsi dalam bentuk kata-kata dan bahasa, pada suatu konteks khusus yang alamiah dan dengan memanfaatkan berbagai metode ilmiah. Dalam komunikasi berbahasa selalu menggunakan tindak kesantunan dalam dialektika. Baik itu dengan teman sejawat maupun dengan guru.

Data sebagai sumber bahan dalam membuat kesimpulan 
dalam penelitian menjadi sangat penting. Data dalam penelitian ini berupa pergeseran tindak kesantunan direktif terhadap guru SDN Polokarto 01 yang berlatar belakang budaya jawa. Sumber data adalah guru dan peserta didik kelas 5 SDN Polokarto 01 Kecamatan Polokarto Kabupaten Sukoharjo. Subyek penelitian ini adalah peserta didik SDN Polokarto 01 sedangkan obyek penelitian pergeseran tindak kesantunan direktif yang dilakukan oleh peserta didik terhadapa guru di lingkungan SDN Polokarto 01. Pengumpulan data dilakukan penulis melalui observasi langsung, simak, rekaman percakapan, catatan dalam kegiatan observasi.

Analisis data dalam penelitian menjadi hal yang utama. Yaitu proses pengorganisasian dan pengklasifikasian data ke dalam bagian dan kelompok data tertentu yang akan disimpulkan oleh penulis. Teknik analisis data yang digunakan adalah padan dan agih. Padan yaitu instrumen atau alatnya berada diluar sedangkan agih adalah alat yang dipakai penelitian adalah bahasa lisan itu sendiri.

\section{HASIL DAN PEMBAHASAN}

Hasil dari penelitian ini adalah menjelaskan atau mendiskripsikan pergeseran tindak kesantunan yang terjadi pada peserta didik kelas 5 SD dengan berlatar belakang budaya jawa adalah sebagai berikut :'

Penelitian dilakukan pada peserta didik kelas 5 SDN Polokarto 01 dengan jumlah 21 anak, dengan berlatar belakang budaya jawa. Dapat dikatakan berlatar belakang budaya jawa karena peserta didik tinggal bersama orang tuanya,yang tinggal diwilayah Kabupaten Sukoharjo Jawa Tengah. Keberagaman tingkat pendidikan dan pembiasaan yang kurang baik dalam keluarga menjadi peluang penentu yang menyebabkan pergeseran kesantunan dalam berinteraksi dengan lingkungan sekitarnya.

\section{[Table 1 about here.]}

[Figure 1 about here.]

Tuturan peserta didik ketika berinteraksi terhadap sesama, maupun dengan orang dengan tingkat usia yanng lebih tua mengalami pergeseran yang bersifat negatif.

\section{[Table 2 about here.]}

Dari beberapa angket dan observasi yang dicatat oleh peneliti, menemukan beberapa tingkah, sikap perilaku dan ucapan dari peserta didik yang mengalami pergeseran tindak kesantunan menurut adab dan adat budaya jawa.

Haryana (2001) menyebutkan faktor yang dapat dijadikan pedoman dalam bertutur tingkah laku dalam berbahasa adalah : (1) Faktor usia, anak kecil terhadap orang tua, (2) Faktor Peprenahan/ kekerabatan, contoh orang dengan usia muda menghormati orang yang usianya lebih tua (3) faktor derajat pangkat, contoh perilaku seorang murid terhadap guru. Jika dilihat dari beberapa faktor tersebut maka bisa dikatakan bahwa peserta didik kelas 5 SDN Polokarto 01 mengalami pergeseran tindak kesantunan berbahasa berlatar belakang budaya jawa yang masih menerapkan unggah-ungguh dan tatakrama berbahasa. Implikasi Hasil Penelitian Kesantunan Berbahasa Jawa dalam Interaksi Guru dan peserta didik

Pertama, terjadinya pergeseran bentuk-bentuk kesantunan berbahasa Jawa baik oleh guru dan peserta didik semata-mata digunakan untuk memperlancar komunikasi dan interaksi dalam pembelajaran. Namun hal tersebut bertolak belakang dengan nilai nilai yang terkandung dalam kaidah derajat tata krama atau unggah ungguh dalam budaya jawa.

Kedua kondisi ini akan tetap menghasilkan suatu pengalaman yang menyenangkan meskipun penutur harus menuntut mitra tutur. Ketika interaksi antara guru dan peserta didik nyaman dan lancar, maka komunikasi akan berjalan efektif dan efisien sehingga tujuan pembelajaran pun dapat tercapai.

Ketiga, peningkatan nilai kesantunan tuturan dengan memperhatikan isi tuturan yang berpihak pada mitra tutur disertai dengan penggunaan unggah-ungguh basa yang benar. Jika dilihat dari aspek isi tuturan, isi tuturan yang menghasilkan tuturan santun, yaitu tuturan yang berpihak pada mitra tutur. Hal ini dapat dicapai dengan pemberian perhatian, kepedulian, bantuan; tidak memaksakan kehendak. Contoh Kesantunan Berbahasa di Lingkungan Pendidikan Formal

Kesantunan dalam berbahasa merupakan salah satu parameter generasi yang memiliki karakter baik dan buruk. Kesantunan berbahasa merupakan awal dalam pembentukkan karakter seseorang yang mencerminkan suatu bangsa. Kesantunan berbahasa ini menjadi tradisi dalam masyarakat Indonesia, begitu kentalnya budaya jawa yang adi luhung masih memegang erat tata krama menempatkan kesantunan dalam prioritas dalam pergaulan.

Pembinaan menjadi sesuatu yang wajib diusahakan melalui pembiasaan. Upaya pembiaasaan itu dapat dilakukan dengan dan ketika berinteraksi dengan siapa pun termasuk dengan orang yang lebih tua. Upaya pembinaan di sekolah dilakukan setiap hari dalam berinteraksi denngan guru, peserta didik yang lebih tua, atau pun dengan teman sebaya dalam jenjang kelas maupun usia. Membiasakan berbicara yang santun, sopan dalam kegiatan pembelajaran atau berinterasi akan menjadikan lisan berucap dengan sadar atau tanpa sadar cara berkomunikasi yang baik. Membiasakan diri mematuhi norma-norma berbahasa akan menjadikan generasi bangsa selalu mematuhi tatanan-tatanan yang ada pada bahasa Indonesia. Lingkungan pendidikan formal maupun informal dapat dijadikan sebagai sarana dalam mentradisikan kesantunan berbahasa.

Pendidikan formal sebagai rumah kedua peserta didik setelah lingkungan keluarga harus mampu menyediakan praktik-praktik kesantunan berbahasa yang memadai sehingga dapat menghasilkan generasi bangsa yang tidak saja memiliki kecerdasan intelektual akan tetapi menghasilkan generasi bangsa yang memiliki kecerdasan emosional dan spiritual. Perpaduan ketiga hal ini akan menghasilkan generasi bangsa yang berkarakter. Implementasi kesantunan berbahasa melalui lingkungan pendidikan formal dapat dilakukan dengan mengintegrasikannya dalam semua mata pelajaran pada semua jenjang pendidikan. Guru harus menjadi contoh teladan dalam mentradisikan kesantunan berbahasa. Strategi Menahan Pergeseran Tindak Kesantunan Berbahasa Peserta Didik kelas 5. Degradasi sikap dan tingkah laku serta tindak kesantunan 
berbahasa pada zaman milineal menjadi amatlah tajam kemrosotannya. Untuk itu diperlukan suatu strategi dalam menahan tindak pergeseran kesantunan berbahasa tersebut. Pranowo (2012:103-104) agar komunikasi dapat terasa santun, tuturan ditandai dengan hal - hal berikut .

1) Angon Rasa, Angon rasa merupakan pengungkapan maksud dalam tuturan dengan mempertimbangkan moment dan waktu yang tepat berkaitan dengan kondisi psikologis mitra tutur. 2) Adu Rasa, pertemukan perasaan Anda dengan perasaan mitra tutur sehingga komunikasi sama - sama dikehendaki karena sama - sama diinginkan. Adu rasa mengadu perasaan antara penutur dan mitra tutur. 3) Empan papan, yaitu menerapkan suatu perkataan pada porsi yang tepat, tempat yanng tepat, suasana yang tepat sehingga antara penutur dan mitra tutur masing masing merasa nyaman dalam berkomunikasi. 4) Sifat rendah hati, mampu menjaga perasaaan mitra tutur sehingga mampu menjaga kerukunan hubungan dan memberi penghormatan kepada orang lain. 5) Sikap hormat, yaitu menjaga agar tuturan selalu menunjukka bahwa mitra tutur diposisikan pada tempat yang lebih tinggi. 6) Sikap tepa salira, yaitu suatu sikap untuk menjaga mitra tutur dengan kondisi yang dialami mitra tutur saat berlangsung sebuah percakapan, dalam hal ini penutur berusaha bersimpati apa yang dirasakan olaeh mitra tutur atau sebaliknya. Dalam berkomunikasi yang dikatakan kepada mitra tutur juga dirasakan oleh penutur begitu sebaliknya.

\section{KESIMPULAN}

Bentuk kesantunan berbahasa siswa dalam interaksi dengan guru berlatar belakang budaya Jawa pada peserta didik Kelas 5 SDN Polokarto 01 , yaitu direpresentasikan dalam modus deklaratif atau berbentuk kalimat berita, modus interogatif atau berbentuk kalimat pertanyaan, dan modus imperatif atau berbentuk perintah. Bentuk kesantunan berbahasa peserta didik dalam interaksi dengan guru berlatar belakang budaya Jawa di peserta didik Kelas 5 SDN Polokarto 01, yaitu direpresentasikan dalam modus deklaratif atau berbentuk kalimat berita, modus interogatif atau berbentuk kalimat pertanyaan, modus imperatif atau berbentuk perintah. Pergeseran kesantunan berbahasa dalam interaksi peserta didik Kelas 5 SDN Polokarto 01 dilihat dari isi tuturan guru dan peserta didik yang mematuhi prinsip kebijaksanaan, prinsip formalitas-tepa selira, prinsip penghargaan dan kerendahan hati-andhap asor, dan prinsip ketidaklangsungan. Nilai kesantunan berbahasa Jawa dalam interaksi peserta didik Kelas 5 SDN Polokarto 01 juga dilihat dari unggah ungguh basa yang digunakan guru dan peserta didik ketika berinteraksi dalam kegiatan pembelajaran sangat rendah.

\section{UCAPAN TERIMA KASIH}

Penulis mengucapkan terimakasih kepada semua pihak yang telah membantu dalam penulisan artikel ini. Dosen pembimbing Sekolah Pasca Sarjana Magister Pendidikan Dasar, Universitas Muhammadiyah Surakarta. Rekan-rekan yang telah memberi masukan, kritik dan saran pada penulisan artikel ilmiah ini. Tentunya tidak dapat kami sebutkan satu persatu dalam tulisan ini. Dan tentunya kepada dewan Redaksi Jurnal Pedogogia Universitas Muhammadiyah Sidoarjo.

\section{REFERENCES}

Ardina Kentary, Abdul Ngalim, Dan Harun Joko Prayitno. 2015. Tindak Tutur Ilokusi Guru Berlatar Belakang Budaya Jawa: Perspektif Gender. Jurnal Penelitian Humaniora, Vol. 16, No. 1, Februari 2015: 61-71.

Astiana Ajeng Rahadini 1), Suwarna 2) (2014). Kesantunan Berbahasa Dalam Interaksi Pembelajaran Bahasa Jawa Di Smp N 1 Banyumas. Jurnal Lingtera, Volume 1 - Nomor 2, Oktober 2014.

Dewi Nurhayati, Raden Hendaryan (2017). Kesantunan Berbahasa Pada Tuturan Siswa SMP. Jurnal LITERASI, Volume 1, Nomor 2, Oktober 2017

Dewi Nurhayati, Raden Hendaryan. (2017). Kesantunan Berbahasa Pada Tuturan Siswa Smp. Jurnalliterasi volume 1 | nomor 2 | oktober 2017

Eka Nur Insani Dan Atiqa Sabardila.(2016) Tindak Tutur Perlokusi Guru Dalam Pembelajaran Bahasa Indonesia Kelas Xi Smk Negeri 1 Sawit Boyolali. Jurnal Penelitian Humaniora, Vol. 17, No. 2, Agustus 2016: 176-184.

Harun Joko Prayitno (2009) Perilaku Tindak Tutur Berbahasa Pemimpin Dalam Wacana Rapat Dinas:Kajian Pragmatik Dengan Pendekatan Jender. Kajian Linguistik Dan Sastra, Vol. 21, No. 2, Desember 2009: 132-146

Harun Joko Prayitno (2010) Perwujudan Prinsip Kerjasama, Sopan Santun, Dan Ironi Para Pejabat Dalam Peristiwa Rapat Dinas Di Lingkungan Pemkot Berbudaya Jawa. Kajian Linguistik Dan Sastra, Vol. 22, No. 1, Juni 2010: 30-46

Harun Joko Prayitno (2011) Teknik Dan Strategi Tindak Kesantunan Direktif Di Kalangan Andik Sd Berlatar Belakang Budaya Jawa. Kajian Linguistik Dan Sastra, Vol. 23, No. 2, Desember 2011: 204-218

Haryana harjawiyana (2001) Marsudi unggah-ungguh Bahasa Jawa. Penerbit Kanisius. Jogjakarta. Halaman 13

Khilyatin Ulin Noor Dan Harun Joko Prayitno.2016. Pergeseran Kesantunan Positif Siswa Kelas Ix Mts $N 1$ Surakarta Berlatar Belakang Budaya Jawa. Kajian Linguistik Dan Sastra, Vol. 1 No. 1, Juni 2016, 17-24

Kurnia Cahyaning Putri; Sarwiji Suwandi; Slamet Mulyono. (2019). Ekspresi Kesantunan Berbahasa Dalam Pembelajaran Bahasa Indonesia Di Smp Muhammadiyah. Jurnal Logat, Volume 7, Nomor 1, Mei 2019

M.Suryadi (2012)Tipe Kesantunan Tuturan Jawa Pada Masyarakat Jawa Pesisir. Kajian Linguistik Dan Sastra, Vol. 24, No. 1, Juni 2012: 69-76

Mursita ekawati. (2017). Kesantunan Semu Pada Tindak Tutur Ekspresif Marah Dalam Bahasa Indonesia. Addabiyat. Vol. I, No. 1, Juni 2017, Hlm. 1-22 Issn (Online): 2549-2047, Issn (Cetak): 2549-1482

Nurul Masfufah (2012) Skala Kesantunan Bentuk Tuturan Direktif Berdasarkan Persepsi peserta didik Di Sman 1 Surakarta. Kajian Linguistik Dan Sastra, Vol. 24, No. 2, Desember 2012: 199-214

Puji Lestari Dan Harun Joko Prayitno.(2015. Strategi Dan Skala Kesantunan Tindak Direktif Mahasiswa Riau Di Lingkungan Masyarakat Berlatar Belakang Budaya Jawa. Jurnal Penelitian Humaniora, Vol. 17, No. 2, Agustus 2016: 135-148.

Rini Indah Sulistyowati, Harun Joko Pravitno, Dan Yakub Nasucha.2013. Perilaku Tindak Tutur Ustad Dalam Pengajian:Kajian Sosiopragmatik Dengan Pendekatan Bilingual. Jurnal Penelitian Humaniora, Vol. 14, No. 1, 26 Februari 2013: 25-40

Subyantoro ( 2012) Pengembangan Buku Pembelajaran Bahasa Indonesia Bermuatan Kesantunan Berbahasa Lintas Budaya: Ancangan Psikolinguistik Pendidikan. Kajian Linguistik Dan Sastra, Vol. 24, No. 2, Desember 2012: 164-175

Zain Syaifudin N. (2013). Implikatur Dan Kesantunan Positif Tuturan Jokowi Dalam Talkshow Mata Najwa Dan Implementasinya Sebagai Bahan Ajar Bahasa Indonesia Di Smk. Jurnal Penelitian Humaniora, Vol. 14, No. 1, 58 Februari 2013: 55-70

Conflict of InterestStatement:Theauthorsdeclarethattheresearch wasconducted in the absence of any commercial or financial relationships that could be construed as a potential conflict of interest.

Copyright $@ 2020$ Mirmanto, Prayitno, Sutopo, Rahmawati, and Widyasari. Thisis an open-access arti- cle distributed under the terms of the Creative Commons Attribution License (CCBY). The use, distributionor reproduction in other forums is permitted, provided the origi- nal author(s) and the copyright owner(s) are credited and that the original publication in this journal is cited, in accordance with accepted academic practice. No use, distri-bution or reproduction is permitted which does not comply with these terms. 


\section{LIST OF FIGURE}

1 Diagram Kebiasaan Siswa Dalam Lingkungan Keluarga Melalui Cek List Angket . 


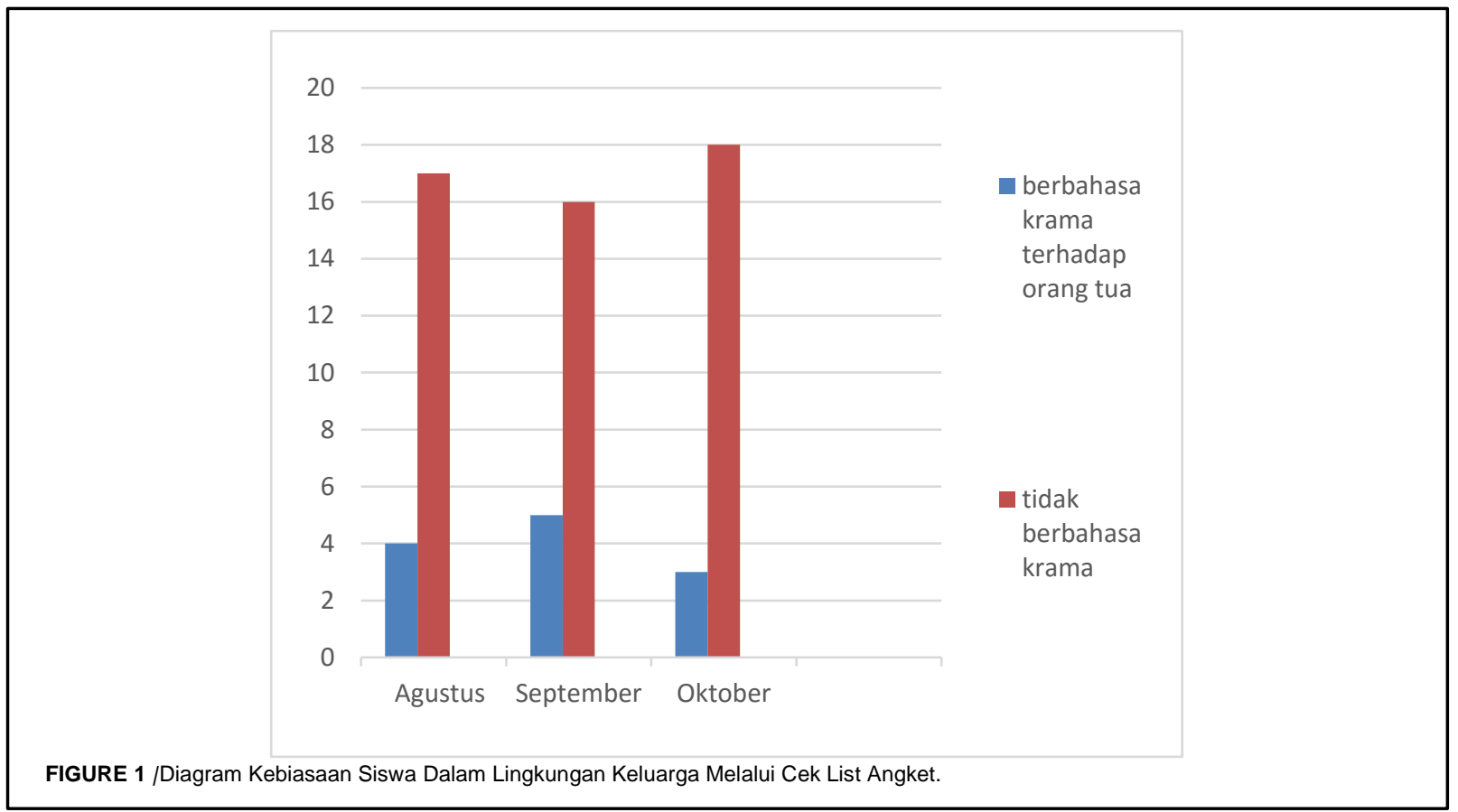




\section{LIST OF TABLES}

1 Kebiasaan Siswa Dalam Lingkungan Keluarga Melalui Cek List Angket ............................................................. 98

2 Tuturan Peserta Didik Terhadap Guru di Sekolah............................................................................................ 99 
TABLE 1/Kebiasaan Siswa Dalam Lingkungan Keluarga Melalui Cek List Angket

Bulan/Tahun Kondisi Tempat Tinggal/

Agustus

Bersama Orang Tua

Berbahasa Terhadap Orang Tua di

Tidak Terbiasaberbahasa Krama di Rumah

September

21

Rumah

4

Oktober

21 
TABLE 2 / Tuturan Peserta Didik Terhadap Guru di Sekolah

No Sesama peserta didik / dengan usia lebih tua

Sesuk teko ra!

ceng, opo koe wes dadi?

Terhadap Guru

Pak guru nganggo jaket

mangkato disik Mas!

pak guru wes teko, cah!

Pak guru, sesuk ulangan nopo? 